\title{
Performance Assessment of Automated Irrigation Network in the Nile Delta
}

\author{
Ahmed Mohsen ${ }^{1}$, Yoshinobu Kitamura ${ }^{2}$, Katsuyuki Shimizu ${ }^{3}$ and Ichiro Kita ${ }^{4}$
}

\begin{abstract}
Egypt is implementing more effective irrigation technology to improve its existing irrigation networks in the Nile Delta. Improvements consist of a demand delivery system using mechanical gate structures and controllers to automatically divert water from one portion of a network to another in the desired amount and sequence. We evaluated the irrigation network system under government management before and after these improvements in the existing irrigation networks in the Nile Delta. The overall results indicate that irrigation networks by traditional rotation systems is unsuitable for irrigation districts located at the end of large irrigation networks in the Nile Delta, while, the demand delivery concept is successful in improving water delivery performance over that of the traditional rotation delivery concept used previously. The new system provided fair shares of water among irrigation districts and allows the irrigation districts to deliver water from main system whenever they need it and any time. In addition, the automation improves efficiency, responsiveness, and flexibility of canal system.
\end{abstract}

Keywords: Water delivery performance; Irrigation district; Automation system; Rotation system; The Nile Delta

\section{Introduction}

Water availability is approaching a crisis due to the pressures of environmental degradation and food demand from increasing populations around the world. Egypt could be vulnerable to water stress under climate changes in the future. Among the possible serious threats resulting from climate change in Egypt, the most important is the rise in sea level that could affect the Nile Delta area. Therefore, the Egyptian government has permitted cultivation of paddy rice in the Nile Delta, anticipating that the freshwater input may counteract the ingress of seawater. Rice is presently cultivated in submerged land (paddy) in coastal plains around the Mediterranean on a total of about 1,200,000 to $1,300,000$ ha. Egypt, with 660,000 ha under paddy cultivation, is the most important rice-producing country in the Mediterranean (Ferrero, 2006). This area consumes around $25 \%$ of Egypt's quota of Nile River flow through the Delta (WAGS, 2008). A factor affecting the Delta water budget is the uncertainty of precipitation and flows in the Nile basin. Precipitation has been predicted to decrease slightly $(5 \%)$ in the future decades over the sub-catchment of the Blue Nile (Soliman et al., 2009). The Blue Nile constitutes around $10 \%$ of the Nile basin, but contributes about $60 \%$ of its total mean annual flow measured at Aswan High Dam in Egypt $\left(84 \times 10^{9} \mathrm{~m}^{3}\right)$. This change may have a severe impact on transboundary flows in the Nile River basin and may especially affect the downstream countries as Sudan and Egypt. In the Delta, water management that balances the scarcity of water for irrigation with highly profitable rice production

${ }^{1}$ Ph.D. Student, United Graduate School of Agricultural Sciences, Tottori University, 4-101 Koyama-cho Minami, Tottori 680-8553, Japan (Corresponding Author) E-mail: mando.ahmedmohsen@gmail.com

${ }^{2}$ Professor, Faculty of Agriculture, Tottori University, 4-101 Koyama-cho Minami, Tottori 680-8553, Japan

${ }^{3}$ Junior Associate Prof., Faculty of Agriculture, Tottori University, 4-101 Koyama-cho Minami, Tottori 680-8553, Japan

${ }^{4}$ Professor, Faculty of Life and Environmental Science, Shimane University, Matsue, Shimane 690-8504, Japan is considered the major challenge facing the Egyptian Ministry of Water Resources and Irrigation (MWRI).

Egypt is attempting to improve existing irrigation networks to increase their reliability and meet water demands more efficiently and effectively. One major initiative is to apply the concept of demand delivery in the main irrigation system by installing automated gates in branch canals in the Nile Delta. The conveyance efficiency is higher for canals operated under demand delivery than for those under the traditional rotation system. A major difference in efficiency is due to seepage losses, as any main canal will leak much more when it has been allowed to dry and then be refilled, whereas continuous supply requires stable water levels in main and branch canals. In the rotation system, the gates of the branch canal control structures are operated manually by the head gatekeeper. In this system it is difficult to adjust gates in response to rapidly changing demand. As a result, there is often too much or too little flow in the canal, and fluctuating water levels in the canal promote bank instability and unreliable supply to secondary canals and tertiary canals. The government has initiated programs to introduce automated operation of water structures since 2002. The performance of improved irrigation system is achieved not only by technical interventions but, more importantly, by reforms in the institutional framework that improve system management, operation, and maintenance.

Because the desired changes will have impacts on decisions of water management and use, the performance of water delivery systems needs to be defined and assessed both before and after the improvements are made. This paper highlights water management in the Nile Delta and presents the operation criteria and mechanisms of the irrigation system by using performance evaluation tools. Performance evaluation is carried out for such purposes as improving irrigation management, determining the overall state of the system, troubleshooting the system, comparing performance from one year to another, or comparing one 
system with another (Molden et al., 1998). Accordingly, in this paper we present the evaluation objectives of an existing traditional Delta irrigation system, and assess the impact on water delivery performance of steps by irrigation districts to improve water management using performance indicators proposed by Molden and Gates (1990). We evaluated the main irrigation network system of the Wasat command area in the Delta over two irrigation seasons (2003 and 2004) before improvements in the system and one irrigation season (2007) afterward.

\section{Material and methods}

\subsection{Study area}

The Wasat command area (Figure 1) is within the Kafr El-Shakh governorate, on the northern edge of the middle Nile Delta, and extends from the outskirts of Kafr El-Shakh city to the shores of Lake Burullus $\left(31^{\circ} 07^{\prime} \mathrm{N}, 30^{\circ} 56^{\prime}\right.$ E). The climate of the northern Delta is typically Mediterranean, with dry, mild summers and cool, wet winters (Eid et al., 2001). The command area is fed from the tail reaches of the main canal, Mit Yazeed, which in turn is supplied from the principal canal, Bahr El-Shebin. Owing to its position at the tail of the feeder canal system, the Wasat command area suffers from inadequate water supplies. This problem is exacerbated by the tendency of farmers to plant more paddy rice area than their licenses stipulate. This area is famous for its rice production, which contributes $40 \%$ of Egypt's total (MSEA, 2008).

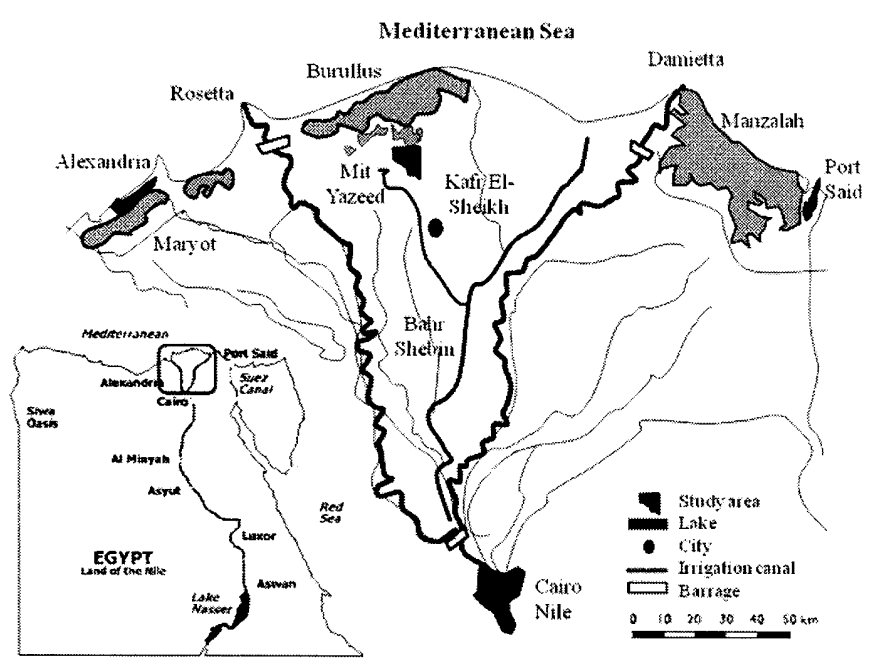

Figure 1: Layout of irrigation networks in Wasat command area (Mohsen et al., 2012)

\subsection{Distribution of irrigation network in the Nile Delta}

Water flows from the Nile to the main users' fields through a network of waterways that consist of a principal canals, main canals, branch canals, tertiary canals called Meskas, and a final field ditch called Marwa, as shown in Figure 2. Government bodies manage the top three levels of canals, the General Directorate for Water Distribution allocating water to the Irrigation Directorates, which in turn distribute it to the Irrigation Districts. The smallest management unit of Egypt's MWRI structure is the district; district engineers are in direct contact with users (Oosterbaan, 1999).

In the primary irrigation system, which operates continuously, water is diverted from the Nile by barrages and from there through a system of main canals. The discharge in the main canal system is regulated by head-control structures, generally equipped with lifting gates. Between these main regulators are cross-regulators at the boundaries between the Irrigation Districts. From the main system, water is admitted to the secondary systems, consisting of branch canals (or delivery canals) by means of lifting gates operated by district engineers under the rotation system. The gates are opened so as to maintain target downstream water levels; however, the cross-regulator discharges are not routinely controlled. The water in the branch canals is distributed to the tertiary canals (meskas), which are on a two- or three-turn rotation. After lifting water from a meska, farmers are free to distribute it over their fields by their own methods.

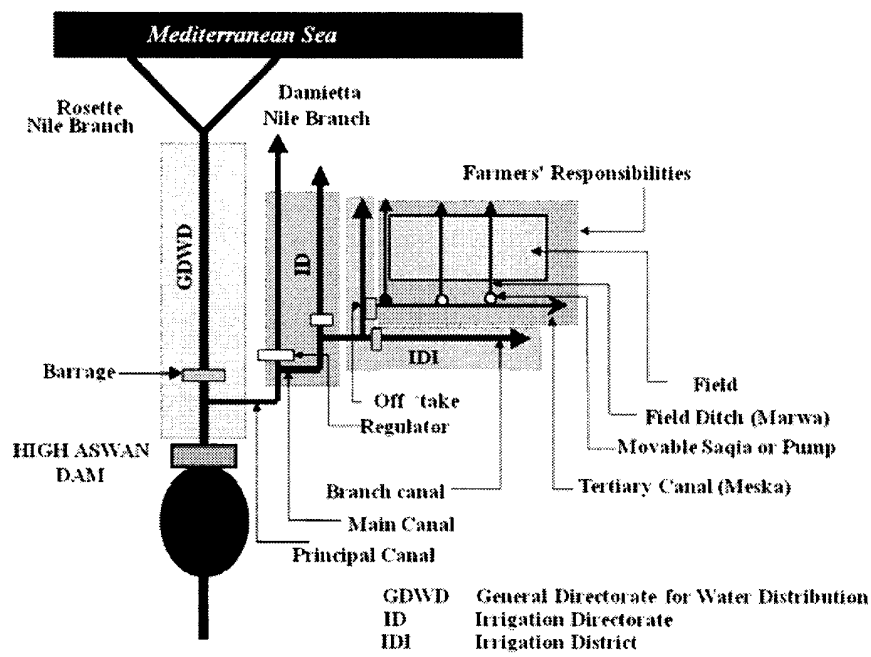

Figure 2: Schematic layout of irrigation systems in the Nile Delta (Source: MWRI)

\subsection{Characteristics of irrigation districts}

In this study, we measured the performance of irrigation networks in three irrigation districts served by Mit Yazeed main canal downstream from the El-Wasat regulator (at $\mathrm{km}$ 34.7 on the main canal), as presented in Figure 3. In each irrigation district, we selected a representative branch canal irrigation system as follows.

The Kafr El-Shakh District represents a headward location below the El-Wasat regulator and serves a command area of about 42,600 ha. Dakalt canal in this district is an earthen branch canal located at $\mathrm{km} 41.00$ on the right side of Mit Yazeed canal. It is about $11.42 \mathrm{~km}$ long and serves a command area of about 2,344 ha. It is operated on a continuous flow system by automatic downstream hydro-mechanical control gates (AVIS gates) by divided into three reaches. This control means that the discharge in each reach is controlled from the downstream end. Changes in flow emanate from tail-end and work sequentially upstream through the system, as shown in Figure 4 (a). 


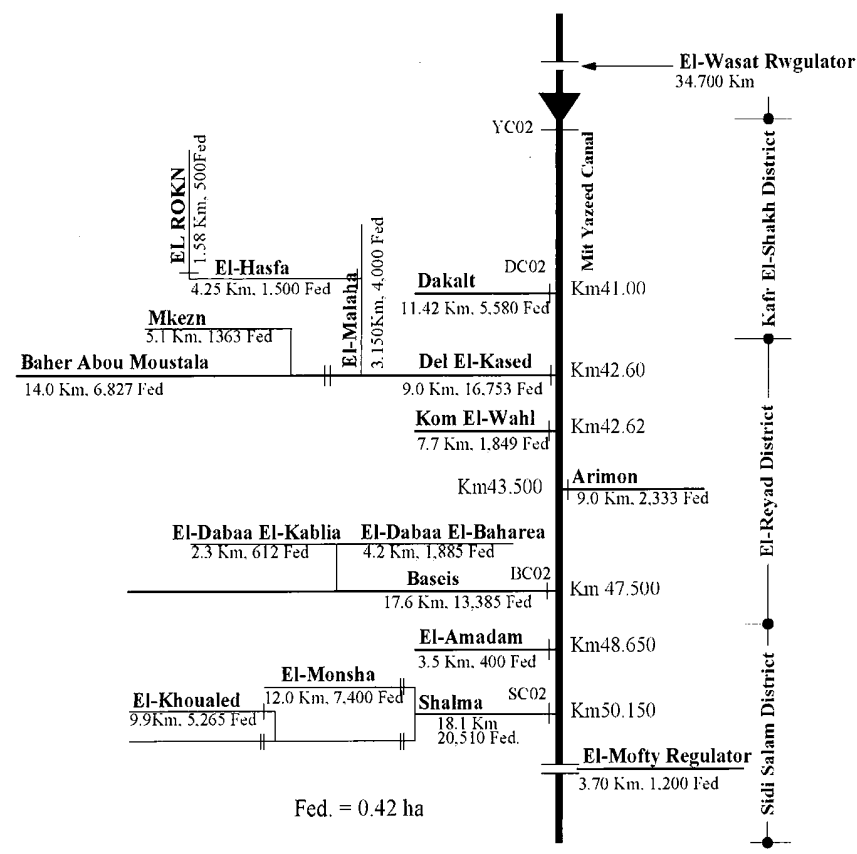

Figure 3: Schematic outlines of the water delivery canals in the study

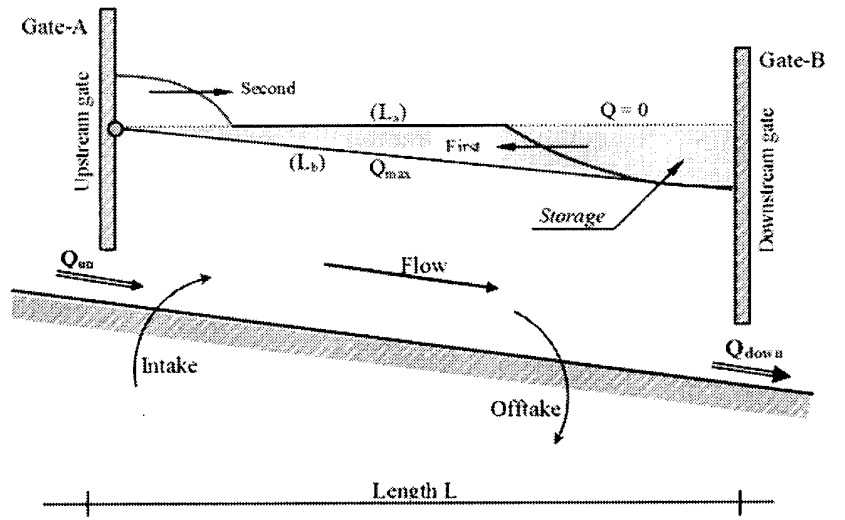

(a)

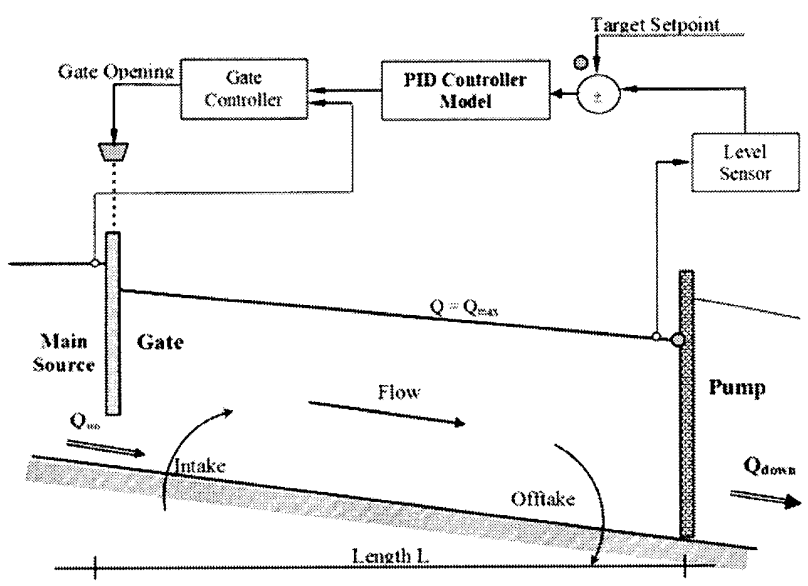

(b)

Figure 4: (a) Automatic downstream controls gates and (b) Using telemetery control technology
The El-Reyad District represents a middle location below the El-Wasat regulator and serves a command area of about 38,000 ha. Baseis canal in this district is an earthen branch canal located at $\mathrm{km} 47.50$ on the right side of Mit Yazeed canal. It is about $17.60 \mathrm{~km}$ long and serves a command area of about 4,805 ha. It is operated on a continuous flow system in three reaches served by three AVIS gates installed as part of the improvement.

The Sidi Salim District represents a tail location below the El-Wasat regulator and serves a command area of about 68,200 ha. Shalma canal in this district is an earthen branch canal located at $\mathrm{km} 50.15$ on the right side of Mit Yazeed canal. It is a relatively large canal and serves around 7,854 ha. It feeds three sub-branch canals in a rotation system. The head regulator of Shalma canal was operated under the supervisory automated system from a single remote location. This control relies on a target water-level sensor in the head of the reach. It works on the premise that at zero discharge the water surface will be horizontal and at maximum discharge the water surface will be parallel to the bed of the canal, shown in Figure 4 (b).

Before improving the system in the study area, the branch and distributary canals were operated under a two-turn or three-turn rotation system. Under two-turn rotation, the canal system was divided into two groups, each opened for 4 days and closed for another 4 days for a total cycle of 8 days. Under three-turn rotation, the canal system was divided into three groups, each opened for 6 days and closed for another 12 days for a cycle of 18 days. After improvements were made, the canals were switched to a demand delivery system (Watanabe, 1995). After improved system by using automatic control, flows are routed through an irrigation water delivery system and water levels are maintained at their set point without human intervention. Initially, the controllers were single variable, local, electromechanical devices that controlled the water level just downstream from an off take gate (Laycock, 2007). Table 1 presents a comparison of the two delivery concepts.

Table 1: Comparison of delivery concepts (Buyalski et al., 1991)

\begin{tabular}{lll}
\hline Consideration & $\begin{array}{l}\text { Rotation } \\
\text { System }\end{array}$ & $\begin{array}{l}\text { Demand } \\
\text { System }\end{array}$ \\
\hline User convenience & Poor & Excellent \\
Irrigation flexibility & Poor & Excellent \\
Water use efficiency & Low & High \\
Ease of canal operation & Easy & Difficult \\
Complexity & Simple & Complex \\
Design capacity of canal & $\sim 40 \%$ & $\sim 80 \%$ \\
\hline
\end{tabular}

\subsection{Determination of performance indicators}

A water supply indicator was used to measure the water delivery performance at the downstream end of the El-Wasat regulator. The indicator of total water supply rate

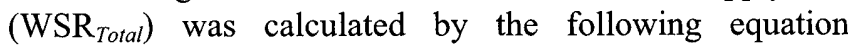
(Kortmaz, 2009; Levine, 1982; Small and Svendsen, 1990): 


$$
\mathrm{WSR}_{\text {Total }}=Q_{\text {DTotal }} / Q_{R \text { Total }}
$$

where $Q_{D \text { Total }}$ is the amount of water diverted $\left(\mathrm{m}^{3}\right)$ into the irrigation network by the El-Wasat regulator, and $Q_{\text {RTotal }}$ is the total irrigation water requirements for the area served by the El-Wasat regulator $\left(\mathrm{m}^{3}\right)$. A value of $\mathrm{WSR}_{\text {Total }}$ equal to 1.0 indicates that enough water is being supplied to meet the water demand.

Water delivery performance through irrigation networks at the irrigation district level was determined according to the following four indicators of adequacy, efficiency, equity, and dependability (Molden et al. 1990). The indicators compare the volume of water delivery $\left(Q_{D i, t}\right)$ with water required $\left(Q_{R i, t}\right)$ in a certain sub-region $(i)$ with area of irrigation block $\left(a_{i}\right)$ during a certain time $(t)$.

Adequacy Indicator: Distribution of required amount $\left(P_{A}\right)$; the objective of adequacy is to deliver the required amount of water over the command area served by the system:

$$
P_{A}=(1 / T) \sum_{T}\left\{(1 / R) \sum a_{i} p_{A i, t}\right\}
$$

where $p_{A i, t}=Q_{D i, t} / Q_{R i, t}$, if $p_{A i, P}>1$, then $p_{A i, t}=1$

Efficiency Indicator: Conservation of water resources $\left(P_{F}\right)$; the objective of water distribution efficiency is to conserve water, matching water deliveries with water requirements:

$$
P_{F}=(1 / T) \sum_{T}\left\{(1 / R) \sum a_{i} p_{F i, t}\right\}
$$

where $p_{F i, t}=Q_{R i, t} / Q_{D i, t}$, if $p_{F i, t}>1$, then $p_{F i, t}=1$

Equity Indicator: Distribution of fair amount $\left(P_{E}\right)$; if equity is interpreted as spatial uniformity of water distribution, then the indicator would be the average relative spatial variability of the ratio of the amount distributed to the amount required over the time period of interest:

$$
P_{E}=(1 / T) \sum_{T} \mathrm{CV}_{R}\left(Q_{D i, t} / Q_{R i, t}\right)
$$

where $\mathrm{CV}_{R}$ is the spatial coefficient of variation of $Q_{D i, t} / Q_{R i . t}$ over the region $R$.

Dependability Indicator: Uniform distribution over time $\left(P_{D}\right)$ indicates the dependability of water distribution as the temporal variability over a region in the ratio of amount distributed to amount required:

$$
P_{D}=(1 / R) \sum_{a_{i}} \mathrm{CV}_{T}\left(Q_{D i, t} / Q_{R i, t}\right)
$$

where $\mathrm{CV}_{T}$ is the temporal coefficient of variation of $Q_{D i, t} / Q_{R, t}$ over time $T$.

In evaluating these indicators, spatial averages were weighted against the surface area of the irrigation network through branch canals to take into account their relative importance. For this study, the region $\left(\Sigma a_{i}=R\right)$ consisted of the total area covered by the selected command areas and the period $(\Sigma t=T)$ covered five months of summer season
(May-September) and seven months of winter season (October-April). Therefore, water deliveries and requirements were calculated for an overall interval of two weeks for branch canals. From the computed values, performance was classified as "good", "fair" or "poor" according to the criteria of Molden and Gates (1990), listed in Table 2.

Table 2: Evaluation criteria for each indicator (Molden et al. 1990)

\begin{tabular}{cccc}
\hline \multirow{2}{*}{ Measure } & \multicolumn{3}{c}{ Performance Class } \\
\cline { 2 - 4 } & Good & Fair & Poor \\
\hline$P_{\mathrm{A}}$ & $0.90-1.00$ & $0.80-0.89$ & $<0.80$ \\
$P_{\mathrm{F}}$ & $0.85-1.00$ & $0.70-0.84$ & $<0.70$ \\
$P_{\mathrm{E}}$ & $0.00-0.10$ & $0.11-0.25$ & $>0.25$ \\
$P_{\mathrm{D}}$ & $0.00-0.10$ & $0.11-0.20$ & $>0.20$ \\
\hline
\end{tabular}

\subsection{Determination of crop water requirements and wa- ter delivery}

Owing to the difficulty of obtaining accurate field measurements, we estimated crop water requirements with the CROPWAT model of the United Nations Food and Agriculture Organization (FAO), which uses Penman-Monteith methods to calculate reference crop evapotranspiration (Smith, 1992). Crop coefficients were developed from the FAO Irrigation Manual (Savva and Frenken, 2002), and water application efficiency (by surface irrigation) was assumed to be $70 \%$ (EHWR, 2003) and conveyance efficiency was assumed to be $80 \%$ for the main canal. The calculations were based on 15-day time steps related to the cropping pattern and calendar.

The performance indicators used in this study required calculation of the water volumes delivered to certain reaches of the branch canals, but such calculations were not possible in the absence of continuous discharge records. However, water levels were continuously monitored using automatic recorders (OTT Thalimedes, Hydromet-Germany) upstream and downstream of the head regulators for El-Wasat and selected branch canals, so it was desirable to establish a relationship between water levels and discharges to enable conversion of these records. We converted flow heights to discharge using individual rating curves for each measurement point. The rating curves of these canals, approximated by geometric shapes, were checked at each

\begin{tabular}{|c|c|c|c|c|}
\hline No. & Canal & Satute & Relation & $R^{2}$ \\
\hline 1 & $\begin{array}{l}\text { Mit } \\
\text { Yazeed }\end{array}$ & Free & $Q=0.13 \times W L^{4.14}$ & 0.88 \\
\hline 2 & Dakalt & Submerged & $O / H^{0.5}=5.65 \times G O-0.05$ & 0.84 \\
\hline 3 & Basies & Submerged & $Q / H^{0.5}=9.09 \times G O-0.84$ & 0.87 \\
\hline 4 & Shalma & $\begin{array}{l}\text { Submerged } \\
\text { Free }\end{array}$ & $\begin{array}{l}Q / H^{0.5}=12.63 \times G O-0.22 \\
O=0.07 \times W I^{6.67}\end{array}$ & $\begin{array}{l}0.92 \\
0.77\end{array}$ \\
\hline
\end{tabular}
measurement point by using the flow velocities measured by current meters and the area of the flow cross section, as presented in Table 3.

Table 3: Head discharge relations for head regulators*

Level (m); $H=$ Head Level $(\mathrm{m})$; and $G O=$ Gate Opening $(\mathrm{m})$ 


\section{Results and discussion}

\subsection{Cropping pattern and values $Q_{D}$ and $Q_{R}$}

Table 4 lists cropping patterns for the Wasat command area at the main canal and the selected branch canals during the irrigation seasons of 2003, 2004, and 2007. The major crops in the study area were rice, cotton, and maize in the summer season and alfalfa, wheat, and sugar beet in the winter season. Remaining crops were classified as either citrus or "other." For summer crops in the whole Wasat area, after the improvements cotton cultivation increased at the expense of maize, while rice remained stable at around $50 \%$. The maximum legal rice quota is $50 \%$ of a branch canal's command area (WAGS, 2008); however, rice accounted for over $55 \%$ of areas served by the branch canal in the head location (Dakalt canal) before improvements and increased to $63 \%$ in 2007 . The proportion of rice remained unchanged in the middle (Baseis) and tail (Shalma) locations. The increase of summer cotton especially favored the area served by the Dakalt canal, where cotton increased to $30 \%$.

For winter crops, sugar beet and wheat decreased, "other" crops increased, and alfalfa had an unclear trend. Alfalfa, a popular winter crop for many farmers as it can either be used as fodder or sold for cash, was especially favored in middle and tail locations, whereas it decreased in the head location after improvement of the system. There were clear trend for wheat crop to decrease in all locations. Sugar beet is considered main crop in this season because it sold as feedstock to sugar factories and is a popular crop. Its rate was unclear trend before and after improved system. Nevertheless, there is a complete absence in the crop composition among the districts of irrigation before and after improved system, even after the development and lack of commitment by government limits.

Delivered and required water volumes $Q_{D}$ and $Q_{R}$ are listed in Table 5 for the main and branch canals. Water delivery was greater in summer than in winter as there was less water demand for winter crops, whereas in summer the gates were opened continuously to meet the demand by paddy fields. The water supply was increased after improved system at downstream main canal and that impacts positively on middle and tail locations of branch canals. It is noticeable that the water delivery for the branch canals after the development was semi-equal of values among themselves. This indicates that the automation system performed fair water distribution among the irrigation districts. In previous years, the head district consistently got a full allocation at the expense of downstream districts. Overall, the water requirement exceeded the water supply both before and after the improvement owing to the study area's location at the end of the irrigation system in the Nile Delta and a chronic water shortage.

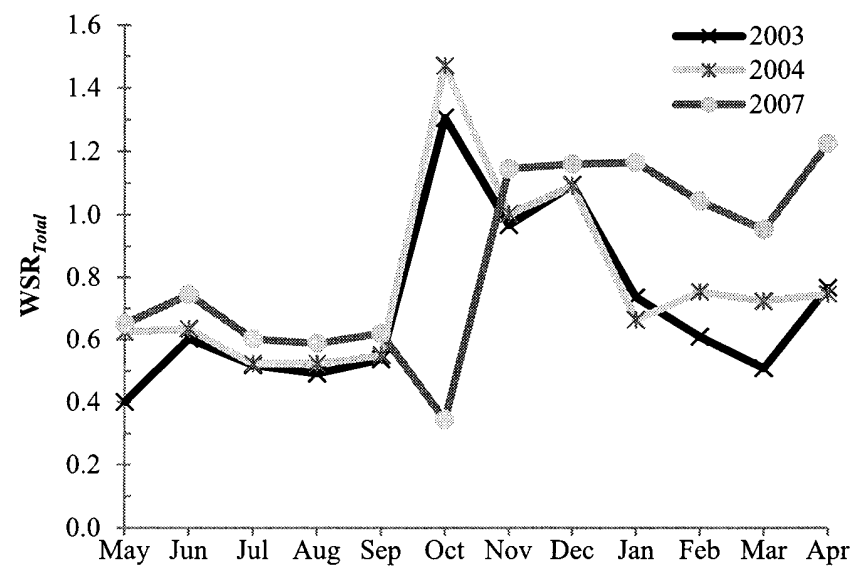

Figure 5: $\mathrm{WSR}_{\text {Total }}$ values downstream of Mit Yazeed

\subsection{Water delivery performance of the system}

Water supply ratio: The values of $\mathrm{WSR}_{\text {Total }}$ in summer months were unchanged after improvement of the system (Figure 5) as there was a continuous shortage of water at El-Wasat due to its location at the end of the Nile Delta. Although there was a $25 \%$ increase of summer water supply with the improved system, this increase was absorbed by the increasing demand for water by cotton instead of maize.

Table 4: Irrigated crop patterns of main canal and branch canals in 2003, 2004 and 2007

\begin{tabular}{|c|c|c|c|c|c|c|c|c|c|c|c|c|}
\hline \multirow{4}{*}{$\begin{array}{c}\text { Crops } \\
(\%)\end{array}$} & \multirow{3}{*}{\multicolumn{3}{|c|}{$\begin{array}{c}\text { Main canal } \\
\text { (El-Wasat } \\
\text { downstream } \\
\text { head regulator) }\end{array}$}} & \multicolumn{9}{|c|}{ Branch canals } \\
\hline & & & & \multicolumn{3}{|c|}{ Head } & \multicolumn{3}{|c|}{ Middle } & \multicolumn{3}{|c|}{ Tail } \\
\hline & & & & \multicolumn{3}{|c|}{ (Dakalt) } & \multicolumn{3}{|c|}{ (Baseis) } & \multicolumn{3}{|c|}{ (Shalma) } \\
\hline & 2003 & 2004 & 2007 & 2003 & 2004 & 2007 & 2003 & 2004 & 2007 & 2003 & 2004 & 2007 \\
\hline Rice & 49 & 50 & 51 & 56 & 57 & 63 & 43 & 44 & 41 & 57 & 52 & 52 \\
\hline Cotton & 16 & 15 & 20 & 21 & 19 & 30 & 15 & 14 & 18 & 37 & 32 & 38 \\
\hline Maize & 17 & 18 & 10 & 11 & 13 & 3 & 12 & 17 & 4 & 5 & 8 & 3 \\
\hline Citrus & 5 & 4 & 7 & 0 & 0 & 0 & 2 & 2 & 2 & 0 & 0 & 0 \\
\hline Other & 13 & 13 & 12 & 12 & 11 & 4 & 28 & 23 & 35 & 1 & 8 & 7 \\
\hline Total Summer & 100 & 100 & 100 & 100 & 100 & 100 & 100 & 100 & 100 & 100 & 100 & 100 \\
\hline Alfalfa & 38 & 27 & 30 & 47 & 37 & 27 & 27 & 22 & 29 & 26 & 26 & 36 \\
\hline Wheat & 33 & 36 & 28 & 39 & 40 & 28 & 31 & 28 & 20 & 44 & 44 & 36 \\
\hline Sugar Beet & 21 & 19 & 16 & 11 & 16 & 15 & 26 & 18 & 18 & 24 & 24 & 15 \\
\hline Citrus & 2 & 3 & 3 & 0 & 0 & 0 & 2 & 2 & 2 & 0 & 0 & 0 \\
\hline Other & 6 & 15 & 23 & 3 & 7 & 30 & 14 & 30 & 31 & 6 & 6 & 13 \\
\hline Total Winter & 100 & 100 & 100 & 100 & 100 & 100 & 100 & 100 & 100 & 100 & 100 & 100 \\
\hline
\end{tabular}


Table 5: $Q_{D}$ and $Q_{R}$ values of main canal and branch canals in 2003, 2004 and 2007

\begin{tabular}{|c|c|c|c|c|c|c|c|c|c|}
\hline \multirow{4}{*}{ 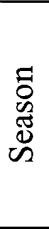 } & \multirow{4}{*}{$\begin{array}{l}\text { 䒿 } \\
\sum^{0}\end{array}$} & \multirow{3}{*}{\multicolumn{2}{|c|}{$\begin{array}{c}\text { Main canal } \\
\text { (El-Wasat down- } \\
\text { stream head regulator) } \\
\mathrm{m}^{3} / \mathrm{ha}\end{array}$}} & \multicolumn{6}{|c|}{ Branch canals } \\
\hline & & & & \multicolumn{2}{|c|}{ Head } & \multicolumn{2}{|c|}{ Middle } & \multicolumn{2}{|c|}{ Tail } \\
\hline & & & & & & $\mathrm{m}^{3}$ & & & \\
\hline & & $Q_{D \text { Total }}$ & $Q_{R \text { Total }}$ & $Q_{\mathrm{D}}$ & $Q_{\mathrm{R}}$ & $Q_{\mathrm{D}}$ & $Q_{\mathrm{R}}$ & $Q_{\mathrm{D}}$ & $Q_{\mathrm{R}}$ \\
\hline \multirow{5}{*}{$\stackrel{\mathscr{\sigma}}{\Xi}$} & May & 626 & 1,564 & 1,230 & 1,711 & 658 & 1,643 & 432 & 1,832 \\
\hline & Jun & 1,104 & 1,833 & 2,066 & 1,989 & 1,416 & 1,807 & 1,425 & 2,183 \\
\hline & Jul & 1,113 & 2,151 & 2,100 & 2,245 & 1,488 & 2,129 & 1,206 & 2,319 \\
\hline & Aug & 1,002 & 2,041 & 1,895 & 2,081 & 1,455 & 2,059 & 1,127 & 2,018 \\
\hline & Sept & 582 & 1,084 & 592 & 1,106 & 697 & 1,059 & 726 & 1,055 \\
\hline \multirow{7}{*}{ 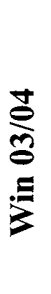 } & Oct & 410 & 314 & 899 & 263 & 360 & 325 & 345 & 241 \\
\hline & Nov & 454 & 468 & 903 & 465 & 455 & 456 & 523 & 445 \\
\hline & Dec & 385 & 352 & 497 & 338 & 310 & 346 & 484 & 331 \\
\hline & Jan & 307 & 417 & 246 & 399 & 477 & 419 & 567 & 418 \\
\hline & Feb & 326 & 536 & 795 & 511 & 425 & 537 & 349 & 555 \\
\hline & Mar & 431 & 848 & 764 & 792 & 568 & 931 & 406 & 951 \\
\hline & Apr & 621 & 810 & 545 & 807 & 585 & 966 & 762 & 902 \\
\hline \multirow{5}{*}{$\begin{array}{l} \pm \\
\Xi \\
\Xi \\
\Xi\end{array}$} & May & 972 & 1,557 & 1,235 & 1,680 & 1,016 & 1,571 & 1,017 & 1,768 \\
\hline & Jun & 1,159 & 1,829 & 1,947 & 1,968 & 1,080 & 1,777 & 1,481 & 2,074 \\
\hline & Jul & 1,128 & 2,160 & 2,066 & 2,243 & 939 & 2,133 & 1,231 & 2,269 \\
\hline & Aug & 1,076 & 2,058 & 1,783 & 2,092 & 948 & 2,070 & 1,366 & 2,030 \\
\hline & Sept & 601 & 1,094 & 621 & 1,118 & 792 & 1,069 & 734 & 1,048 \\
\hline \multirow{7}{*}{ 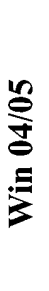 } & Oct & 472 & 320 & 941 & 267 & 393 & 394 & 446 & 241 \\
\hline & Nov & 474 & 472 & 700 & 461 & 544 & 490 & 439 & 445 \\
\hline & Dec & 379 & 347 & 841 & 338 & 622 & 360 & 284 & 331 \\
\hline & Jan & 273 & 411 & 313 & 407 & 274 & 413 & 261 & 418 \\
\hline & Feb & 379 & 503 & 942 & 521 & 597 & 434 & 328 & 567 \\
\hline & Mar & 602 & 833 & 856 & 834 & 488 & 763 & 525 & 978 \\
\hline & Apr & 597 & 800 & 693 & 804 & 700 & 817 & 517 & 949 \\
\hline \multirow{5}{*}{$\underset{\Xi}{\Xi}$} & May & 976 & 1,663 & 1,088 & 1,859 & 1,047 & 1,760 & 993 & 1,852 \\
\hline & Jun & 1,319 & 1,925 & 1,725 & 2,183 & 1,315 & 1,866 & 1,307 & 2,160 \\
\hline & Jul & 1,279 & 2,163 & 1,707 & 2,322 & 1,493 & 2,127 & 1,137 & 2,293 \\
\hline & Aug & 1,204 & 2,003 & 1,474 & 2,053 & 1,653 & 2,037 & 1,332 & 2,003 \\
\hline & Sept & 691 & 1,078 & 691 & 1,108 & 736 & 1,037 & 599 & 1,026 \\
\hline \multirow{7}{*}{$\begin{array}{l}\stackrel{\infty}{\stackrel{\infty}{5}} \\
\stackrel{5}{5} \\
\vdots\end{array}$} & Oct & 138 & 402 & 904 & 393 & 725 & 432 & 655 & 304 \\
\hline & Nov & 577 & 504 & 879 & 495 & 414 & 494 & 640 & 472 \\
\hline & Dec & 430 & 370 & 615 & 362 & 325 & 369 & 449 & 345 \\
\hline & Jan & 486 & 417 & 339 & 412 & 754 & 412 & 510 & 407 \\
\hline & Feb & 466 & 447 & 368 & 390 & 628 & 421 & 389 & 477 \\
\hline & Mar & 675 & 708 & 1,012 & 658 & 1,131 & 763 & 724 & 808 \\
\hline & Apr & 835 & 681 & 759 & 681 & 1,123 & 937 & 1,835 & 873 \\
\hline
\end{tabular}

For the winter season, $\mathrm{WSR}_{\text {Total }}$ values rose to 1.1 in all months with the improved system, showing that the $31 \%$ increase in winter water supply covered the water requirement in the area served. It is apparent that the government's irrigation director of the study area released more water than before to make the supply compatible with cropping patterns in the winter season, a change made possible by the improvements.

\subsection{Molden's indicators for the delivery system}

This section uses Molden's indicators to analyze water delivery performance through irrigation months as a spatial function as a line chart, and to analyze the difference from head to tail of the irrigation system as a temporal function, presented in Figure 6 as a column chart.

\subsubsection{Spatial values of performance indicators}

The adequacy values for the spatial function in summer and winter months are given in Figure 6 (a) and (b), respectively. The highest $P_{A}$ values before improvement were in June (around 0.8) in summer and in October and November (around 0.9 to 1.0 ) in winter. After the improvements, $P_{A}$ values were less variable, ranging from 0.6 to 0.7 in summer and 0.9 to 1.0 in winter. 


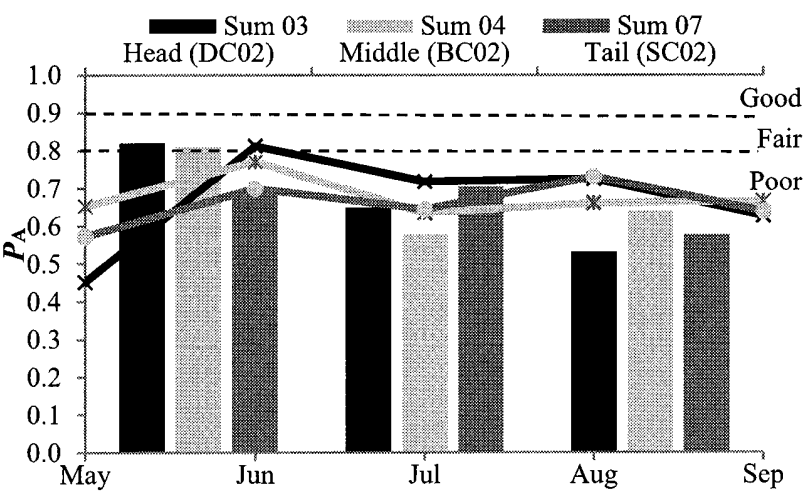

(a) $P_{\mathrm{A}}$ values in summer season

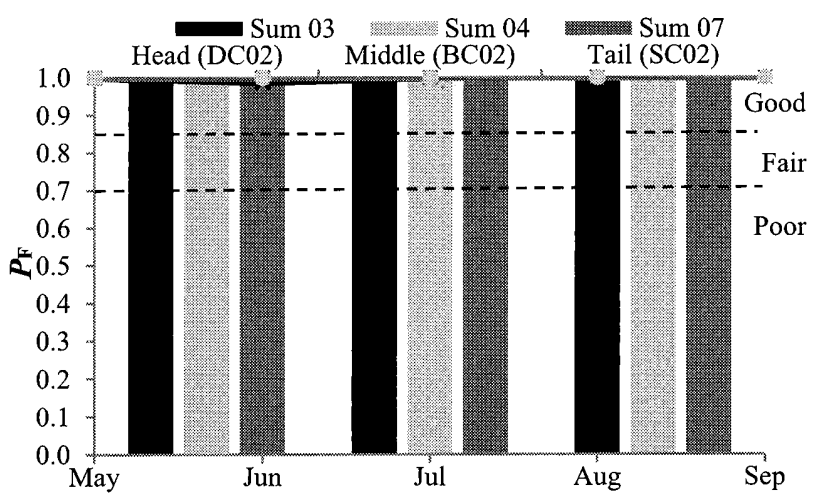

(c) $P_{\mathrm{F}}$ values in summer season

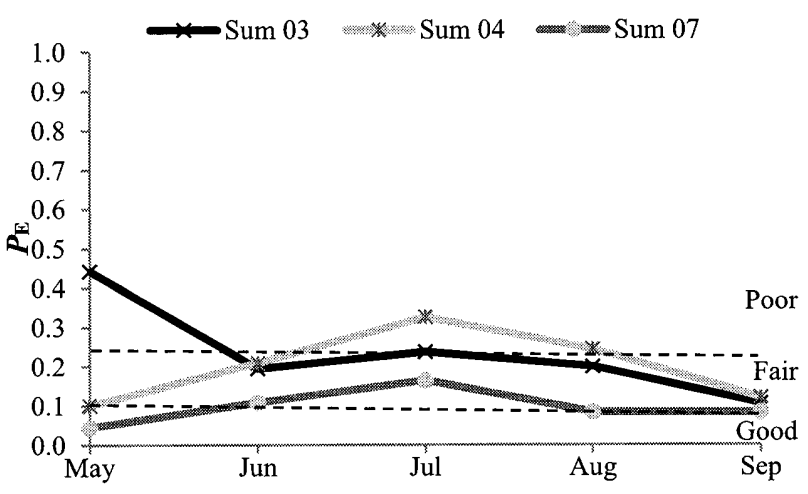

(e) $P_{\mathrm{E}}$ values in summer season

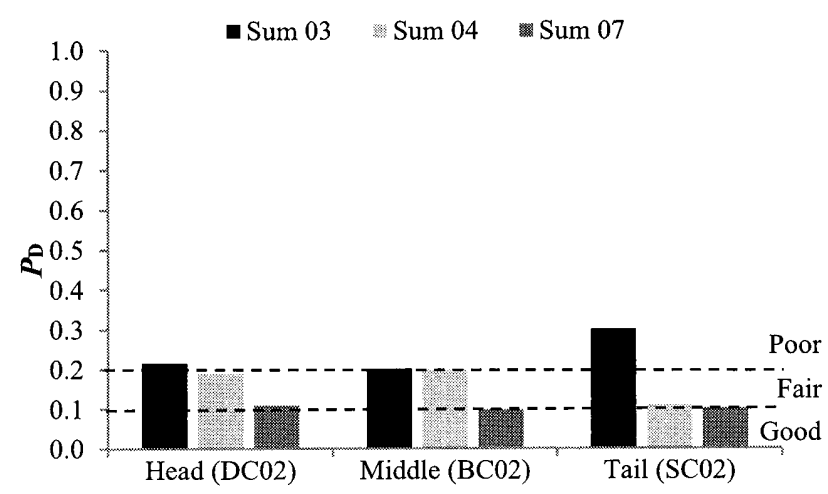

(g) $P_{\mathrm{D}}$ values in summer season

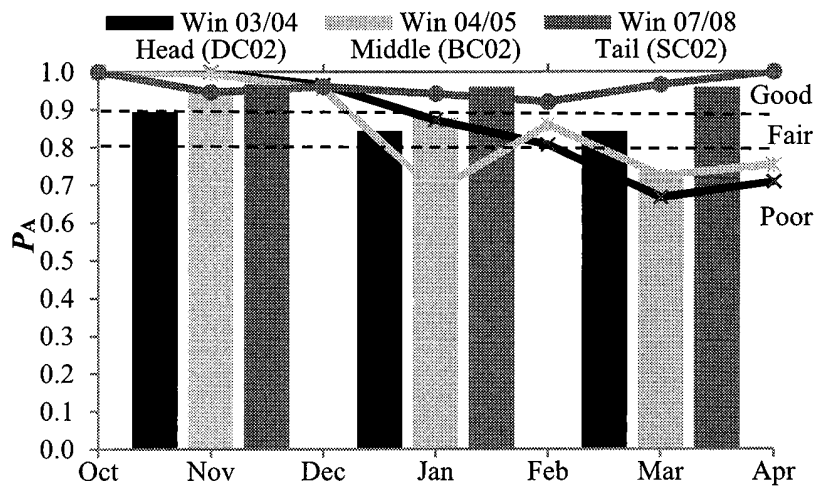

(b) $P_{\mathrm{A}}$ values in winter season

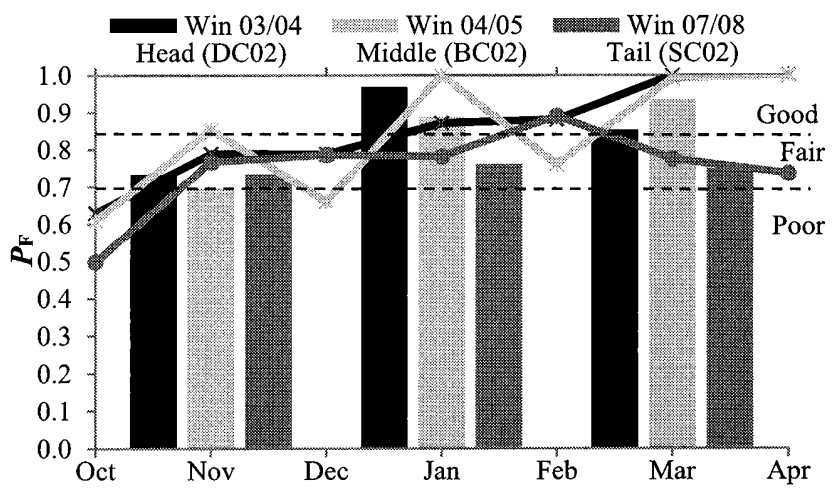

(d) $P_{F}$ values in winter season

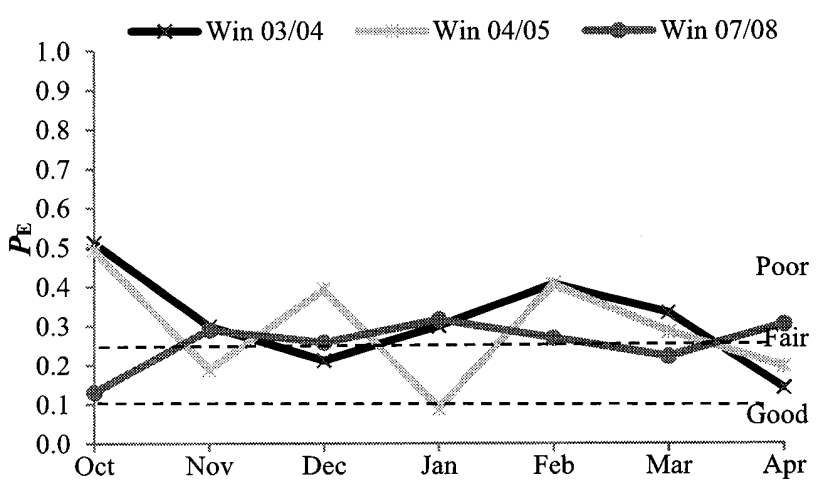

(f) $P_{\mathrm{E}}$ values in winter season

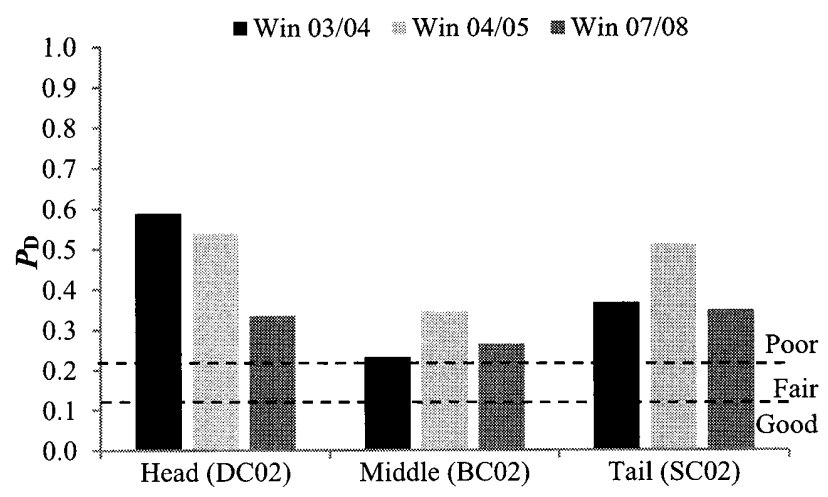

(h) $P_{\mathrm{D}}$ values in winter season

Figure 6: Spatial and temporal values of $P_{A}, P_{F}, P_{E}$, and $P_{D}$ for irrigation seasons 2003, 2004 and 2007 
These values demonstrate improved performance of water delivery, although values of $P_{A}$ remained poor in summer because of the region's chronic water shortage. The automated systems succeeded in keeping the ratio of water delivery to water demand equable through irrigation months, especially in winter season unlike the rotation system in which this ratio decreased over the course of the growing season as water demands rose. This indicates that the automation system applies to canal systems that are primarily demand-oriented and usually is associated with delivery systems.

Spatial values of efficiency $P_{F}$ were 1.0 in all summer months before and after improved system (Figure 6 (c)), a reflection of the extreme water demands of the most consuming crops for water as rice paddy, cotton and maize crops than available water deliver in the end of irrigation systems in the Nile Delta. For the winter season, efficiency values fluctuated between 0.6 and 1.0 before the improvements, a reflection of the shortcomings of the rotation irrigation system in allocating water through peak's months among the irrigation systems of the districts (Figure $6(d)$ ). After the improvements, the efficiency rates were closed to 0.73 and fair in all months because the automation improves efficiency, responsiveness, and flexibility of canal system by responding water level on their downstream side.

Values of the equity indicator $P_{E}$ for summer and winter seasons, presented in Figure 6 (e) and (f), respectively, were almost uniformly good, lower (better) than 0.1 in summer season and closed to 0.25 in winter season, after the improvements. This performance confirms the more equitable water delivery among irrigation districts after the improvements, despite the ongoing water shortage in this area in summer. This indicates that the automation system allows the branch canals to take water from the main canal whenever they need it by applying continuous flow in the same time. Before the improvements, equity was only fair in summer and fair to poor in winter because of abuse of the rotation principle as well as damage to head regulators of the system that allowed leakage. They were not cooperated with irrigation districts to receive their share of the constant available water supply.

\subsubsection{Temporal values of performance indicators}

For the system before improvements, the temporal values of $P_{A}$ for the head location were higher than other locations (Figure 6 (a) and (b)). This is inevitable for the head irrigation district, nearest to the main canal, when using a rotation system. $P_{A}$ for the head location was fair in summer and good in winter, while for the downstream locations it was generally poor. After the improvements, $P_{A}$ values at different locations were nearly always equal. The strongest effect identified is when continuous flow is fully operational among irrigation districts. This indicates the success of the automated gates in allocating water, especially for the tail location. The $P_{A}$ grade for all locations in summer was poor due to inadequate crop planning and good in winter season due to available water supply through this season than demand.

The temporal values of $P_{F}$ in summer before and after improvements (Figure 6 (c)) were uniformly good, not because of more efficient water use by irrigation systems, but because of water shortages due to owing to the study area's location at the end of the irrigation system and intensive cultivate paddy rice. For winter (Figure $6(\mathrm{~d})$ ), the relatively low values of $P_{F}$ for the head location before improvements indicate that more water was delivered to the irrigation system than required, in contrast to other locations that faced water shortages. After improvements, the values of $P_{F}$ were nearly identical, indicating high efficiency, despite being only fair. Passive automation with local control in the form self-regulating constant downstream level gates requires in-built intermediate storage.

The dependability indicator $P_{D}$ was generally poor (around 0.2) in summer season (Figure $6(\mathrm{~g})$ ) for all three districts and values fluctuated in winter season (Figure 6 (h)) before improvements, because the head location got its full share of water under the rotation system, while the other sites got incomplete shares as a result of the chronic regional water deficit. After improvements, the values improved to 0.1 (good) in summer and 0.3 in winter, and were essentially equal in all three locations. The reason was the success of applying continuous flow through the main canal rather than the previous rotation system. It means that the farmers in any irrigation district could plan for a dependable delivery of water, even of an inadequate supply, by growing different crops.

Table 6: Water delivery performance of irrigation system before improvements (2003/2004) and after improvements (2007)

\begin{tabular}{ccccccc}
\hline & \multicolumn{7}{c}{ Irrigation system } \\
\cline { 2 - 7 } & Sum & Sum & Sum & Win & Win & Win \\
& 03 & 04 & 07 & $03 / 04$ & $04 / 05$ & $07 / 08$ \\
\hline$P_{\mathrm{A}}$ & 0.67 & 0.68 & 0.66 & 0.86 & 0.85 & 0.96 \\
$P_{\mathrm{F}}$ & 1.00 & 1.00 & 1.00 & 0.85 & 0.84 & 0.75 \\
$P_{\mathrm{E}}$ & 0.23 & 0.20 & 0.10 & 0.31 & 0.29 & 0.26 \\
$P_{\mathrm{D}}$ & 0.24 & 0.16 & 0.10 & 0.40 & 0.47 & 0.32 \\
\hline
\end{tabular}

\subsubsection{Average values of performance indicators}

Average values of the four performance indicators are presented for the system before and after improvements in Table 6. $P_{A}$ in summer was consistently below 0.7 before and after improvements, and in winter it increased from around 0.85 to over 0.95 after improvements. $P_{F}$ in summer was consistently 1.0 before and after improvements, and in winter it decreased from about 0.84 to 0.75 after improvements. Values of $P_{E}$ and $P_{D}$ were consistently better after improvements. Water delivery performance of the system was fair or good in terms of adequacy, equity, and dependability and good in terms of efficiency. After improvements, adequacy was poor in summer and good in winter, and the efficiency, equity, and dependability were good at summer season and were poor at winter season. After improved system, $P_{A}$ was stable in summer and improved in winter seasons. $P_{F}$ was a constant during the summer season while worsen in the winter season as result of availability of water 
without the use. Indicators of $P_{E}$ and $P_{D}$ are advanced in summer and winter seasons after improved systems. The average values of the four performance indicators indicate systemic water delivery problems before improvements. The reasons stem from irregularities in the use of the rotation system among irrigation districts, due to the human presence in operations and damage or disrepair of regulators. However, after improvements including automated water delivery among irrigation systems, performance improved by awarding fair shares of water among irrigation districts and dependable, consistent deliveries.

\section{Conclusions}

This study evaluated the water delivery performance among irrigation districts served at downstream the El-Wasat regulator by comparison of the irrigation networks before and after improvements to the systems, using the indicators of adequacy, efficiency, equity, and dependability proposed by Molden and Gates (1990). The performance indicators required calculation of water volumes delivered to branch canals, which we established through the relationship between recorded water levels and discharges in the study area. Crop water requirements were estimated with the CROPWAT model.

We conclude that the traditional rotation delivery system does not properly serve all parts of the irrigation network because there are not adequate control points to distribute water equitably among them. As a result, the performance for tail locations in the canal system is worse than that for headward locations. Thus, irrigation by rotation systems is unsuitable for irrigation districts located at the end of large irrigation networks in the Nile Delta. Contributing to this result are chronic water shortages in the study area during irrigation seasons and the absence of crop production planning among different locations served by the main canal, especially for rice cultivation in summer. In addition, there is no cooperation among irrigation districts in the distribution of water, such that headward locations receive full deliveries at the expense of downstream locations. We showed that irrigation networks using automated systems improved water delivery performance by delivering more equal shares of water to districts and allowed the irrigation districts to delivery water from main system whenever they need it and any time. In addition, the automation improves efficiency, responsiveness, and flexibility of canal system.

\section{Acknowledgments}

We thank the Global Centre of Excellence for Dry-land Science (GCOE) funded by the Japanese Ministry of Education, Culture, Sports, Science, and Technology in the Arid Land Research Centre of Tottori University for the funding on this research. This work was supported by the Water Management Research Institute (WMRI) of the National Water Research Centre (NWRC) in Egypt.

\section{References}

[1] Buyalski, C. P., Ehler, D. G., Falvey, H. T., Rogers, D. C., and Serfozo, E. A. (1991): Canal systems automation manual, Volume 1. First edn. U.S. department of the interior, Bureau of reclamation, USA, pp.1-113.
[2] EHWR: Egyptian Handbook for Water Resources (2003): Module 1: Management of Irrigation and Drainage Networks, National Water Research Centre, Cairo, pp.1-1450, (in Arabic)

[3] Eid, H. M., El-Marsafawy, S. M., and Ouda, S. A. (2001): Assessing the impact of climate on crop water need in Egypt: the CROPWAT analysis of three districts in Egypt, Agriculture Research Center, Cairo, pp.1-35.

[4] Ferrero, A. (2006): Challenges and opportunities for a sustainable rice production in Europe and Mediterranean area, $J$. of Paddy Water Environ, (4), pp.11-12. doi:10.1007/s 10333-005-0025-3.

[5] Laycock, A. (2007): Irrigation systems (design, planning and construction), British library, London, UK, pp.1-285. ISBN-13: 9781845932633.

[6] Levine, G. (1982): Relative water supply: an explanatory variable for irrigation systems, Technical Rep, No. 6, Cornell Univ, Ithaca, N.Y., pp.1-46.

[7] Korkmaz, N., Avci, M., Unal, H. B., Aski, S., and Gunduz, M. (2009): Evaluation of the water delivery performance of the Menemen left bank irrigation system using variables measured on-site, J. Irrig. Drain. Eng, 135(5), pp.633-642. doi:10.1061/(ASCE)IR.1943-4774.0000053.

[8] Mohsen, A., Kitamura, Y., and Shimizu, K. (2012): Assessment of irrigation practices at the tertiary canal level in an improved system-a case study of Wasat area, the Nile Delta, J. of Paddy Water Environ., 11(1-4), pp.445-454. ISSN 1611-2490. doi: 10.1007/s10333-012-0335-1.

[9] Molden, D. J., and T.K. Gates. (1990): Performance Measures for Evaluation of Irrigation Water Delivery Systems, J. Irrig. Drain. Eng. ASCE, 116(6), pp.804-823.

[10] Molden, D. J., Sakthivsdivel, R., Perry, C.J., and Klozen, W. H. (1998): Indicators for comparing performance of irrigated agricultural system, Report No. 20, International Water Management Institute, Colombo, Sri Lanka, pp.1-26.

[11] MSEA: Ministry of State for Environment Affairs (2008): Environmental characterization of Kafr El-Sheikh city, Environment Affairs Sector, Kafr El-Sheikh, Egypt, pp.1-133, (in Arabic).

[12] Oosterbaan, R. J. (1999): Impacts of the irrigation improvement project, Egypt, on drainage requirements and water savings, Report to the Egyptian-Dutch Advisory, pp.1-36. Available via www.waterlog.info.

[13] Savva, A.P., and Frenken K., (2002): FAO (Irrigation Manual): Module 4 Crop Water Requirements and Irrigation Scheduling, Sub-Regional Office for East and Southern Africa, Harare, pp.1-122.

[14] Small, L. E., and Svendsen, M. (1990): A framework for assessing irrigation performance, Irrig. Drain. Syst., 4, pp. 283-312.

[15] Smith, M. (1992): CROPWAT: A Computer Program for Irrigation Planning and Management. FAO Irrigation and Drainage Paper 46, Rome, pp.1-126. ISSN 0254-5284

[16] Soliman, E. S. A., Aty Sayed, M. A., and Jeuland, M. (2009): Impact Assessment of Future Climate Change for the Blue Nile Basin, Using a RCM Nested in a GCM. Nile Basin Water Eng. Scien. Mag., 2, pp.15-30.

[17] WAGS: Water Awareness and Guidance Sector (2008): Rice Problem in Egypt. Ministry of Water Resources and Irrigation. Cairo. Egypt, pp.1-24. (in Arabic).

[18] Watanabe, T. (1995): Rice cultivation in the Nile Delta. In: Tabuchi, T., and Hasegawa, S. (ed) Paddy field in the world, JSIDRE, Japan, pp. 53-68. ISBN 4-88980-077-8C3061. 